\title{
Neurofeedback training to increase of cognitive skills in patient with traumatic brain injury (TBI)
}

\begin{abstract}
The aim of this case analysis was to study the effect Neurofeedback (NFB) training protocol in attention, memory, verbal fluency and speed in an 18-year-old woman patient who suffered a severe TBI due to major car accident one year ago, who presented disoriented, with both, anterograde memory and attention problems at the time of neuropsychology consultation. Additionally, absence crises, quadrantanopsia and left divergent strabismus was reported.

Electroencephalogram study reports a predominance in a right parieto-temporal slow brain activity. Thus, we proposed 20 sessions of neurofeedback training protocol aimed to increase beta wave and inhibit theta wave. After four months, the patient experienced a significant improvements in attention, coding, working memory and processing speed. The cognitive performance improvements was associate, with a slow brain waves percentage decrease, which according to previous research could be related with low blood flow.
\end{abstract}

Volume 8 Issue | - 2018

\author{
Manuel E Riaño-Garzón, Edgar Alexis Díaz \\ Camargo \\ Psychology Program, Universidad Simón Bolívar, Colombia
}

Correspondence: Manuel E Riaño Garzón, Psychology Program, Universidad Simón Bolívar, Av. 4E number 6-49 Office I I2, Cucuta-Colombia,Tel 57-589I793,

Emailm.riano@unisimonbolivar.edu.co

Received: August 15, 2017 | Published: January 05, 2018

Keywords: Neurofeedback, Traumatic brain injury, Neuropsychology, Cognitive stimulation, Neuropsychological assessment

\section{Abbreviations: TBI, Traumatic brain injury; NFB, Neurofeedback \\ Introduction \\ TBI was defined as damage to the brain by external mechanical forces, an injury that may be accompanied by physical, cognitive, behavioral and emotional alterations. ${ }^{1}$ According to the National Administrative Department of Statistics DANE, of the total number of deaths in Colombia, Trauma occupies the first place with $40.4 \%$ of the total distributed as follows: homicides $69 \%$, traffic accident $15.9 \%$, other accidents $7.6 \%$, suicides $3.4 \%$, and other traumas $3.3 \% .^{2}$}

The focal neuropsychological effects of TBI (aphasias, aphasias, agnosias, alexias, acalculias and amnesias, frontal syndrome, among others) depending on the etiology and are essentially a consequence of the presence of bruises and lacerations due to the effect of immediate impact, hemorrhages or infarcts in borderline areas as a consequence of hypoxia situations. ${ }^{3}$

The neuropsychological functions affected by a TBI, mainly, are attention, concentration, memory, speed to process information, perception, intelligence, language, emotional and behavioral disorders. ${ }^{4}$ However, memory is one of the higher functions more likely to be altered after suffering a TBI. In case of temporal unilateral injuries, learning for a specific type of material may be compromised. ${ }^{5}$

Among the therapeutic alternatives in TBI, we highlight treatments that increase cognitive skills, among which we can mention cognitive stimulation, which consists of performing exercises to increase memory, language and executive functions ${ }^{6,7}$ and training in NFB, a technique that relies on the use of hardware and software, aimed at instructing the person to voluntary control of brain electrical activity. ${ }^{8}$

\section{Case presentation}

An 18 years old Colombian woman, who was entry to Neuropsychology clinical service due to severe TBI of traffic accident, with subdural and epidural hematomas. In the initial interview, time disorientation was identified, with subjective complaint of memory loss and motor coordination.

In the clinical history was reported absence crises, easy crying and suicidal ideation in the last month; no apparent motor deficit, mild right hyperflexia, slightly unstable gait with acceptable coordination. Additionally, quadrantanopsia was reported in the left eye and left divergent strabismus. The electroencephalogram report indicates an abnormal waking state, with a predominance of slow activity (theta band 4 to $7 \mathrm{~Hz}$ with an amplitude of 40 to $90 \mu \mathrm{V}$ ) in the right parietotemporal area. In posterior areas, bisynchronous and irregular activity was found from 8 to $11 \mathrm{~Hz}$, amplitude from 20 to $50 \mu \mathrm{V}$. In anterior brain regions, a beta band of 20 cycles and $10 \mu \mathrm{V}$ predominates. Poor physiological drag response with photostimulation.

\section{Design}

A quasi-experimental pretest-posttest. ${ }^{9}$

\section{Instruments}

Programa integrado de exploración neuropsicológica Test Barcelona: PIEN-B $B^{10}$ instrument aimed at the evaluation of higher mental activities in Spanish speakers, which offers standardization to percentiles according to age and educational level.

Wechsler intelligence scale III: ${ }^{11}$ an instrument for to calculate the intellectual profile and that was used to evaluate speed of processing, attention and working memory. This instrument offers conversion to scalar scores for each subtest.

Rey complex figure: ${ }^{12}$ which was used to evaluate visual memory.

\section{Procedure}

The intervention program was developed in three phases: a) Evaluation of attention processes, memory and language B) Implementation of NFB Protocol and c) Post-intervention assessment.

The NFB program was developed in three sessions per week, each session lasting 30 minutes. A training NFB protocol was used directed 
to increase the brain-wave of $12-16 \mathrm{~Hz}$ (beta wave) and inhibition the slower brain-wave of 4-7 Hz (theta wave) in a monopolar montage. Twenty training sessions were conducted.

\section{Results}

The NFB training program was useful in increasing visual attention, attentional span, short-term verbal and visual memory,

Table I Differences in pretest-posttest cognitive performance. Standard Scores processes where equal to above-average performances are observed according to the participant's age (Table 1). In addition, there were improvements in long-term memory, working memory and verbal fluency; however, these results did not reach the expected levels. Improvements in cognitive performance due to NFB are explained by the modification of the cortical electrical activity, where a decrease in theta wave was observed from an initial percentage of 28.75 to a final percentage of 19.80 (Figure 1).

\begin{tabular}{llll}
\hline Barcelona Test* & & Baseline Percentile & Follow-up Percentile \\
\hline $\begin{array}{lll}\text { Cognitive Process } \\
\text { Perception and visual }\end{array}$ & Subtest & 10 & 95 \\
attention & Overlapping images & 20 & 50 \\
Attentional span & Direct Digits & 10 & 30 \\
Verbal fluency & Semantics & $>10$ & 10 \\
Visual memory & Phonemic & 30 & 95 \\
& Rey complex figure /encode & 10 & 40 \\
Verbal memory & Rey complex figure - Long term memory & 10 & 50 \\
& Text - Short term memory & $>10$ & 20 \\
Working Memory & Text - Long term memory & 20 & 50 \\
Wechsler Intelligence Scale** & Inverse digits retention & $>10$ & 30 \\
Cognitive Process & Subtest & & Follow-up Scalar \\
Working memory & Letters and numbers & Baseline Scalar & 9 \\
Visual attention & Search symbols & 7 & 11 \\
$*$ Average= Percentile 50 & Keys & 9 & 10 \\
$* *$ Average= Scalar Score 10 & & 7 & \\
Source: Own Elaboration & & &
\end{tabular}

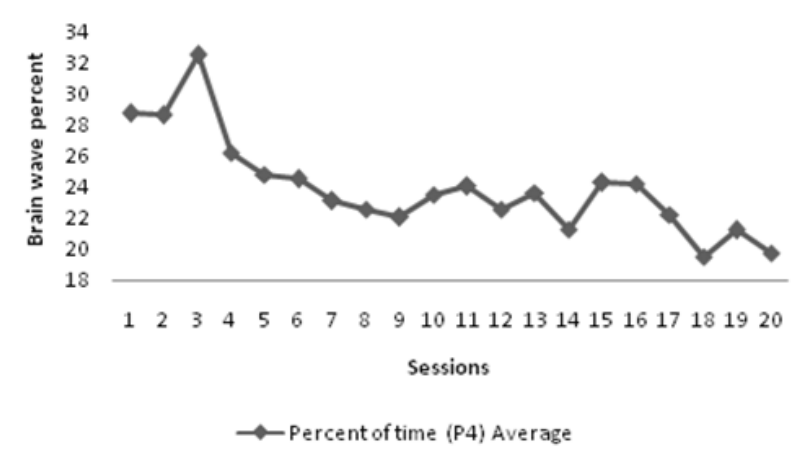

Figure I Average slow wave results per session. Source: Prepared by the authors based on the results of electroencephalogram register.

\section{Discussion}

Cognitive impairment, especially attention and memory, stands out in the TBI, ${ }^{13}$ for this reason, the object of study was to increase attention, memory, verbal fluency and speed through a NFB training protocol. The results showed that NFB generated improvement in the cognitive processes of the patient with TBI after a stimulation process of 30 sessions compared to its initial evaluation.

The observed increases in visual and auditory attention, coincide with findings of Bernal:; ${ }^{14}$ Gadea, Aliño, et al., ${ }^{15}$ who found significant improvements in attention skills by NFB. This finding can be explained by the synchronization of the EEG, which showed asymmetry in the electrical activity of the brain, specifically with a predominance of slow activity in the right hemisphere, Therefore, the rehabilitation of the attention must point to the attention circuits affected by the neurological damage that supports the attention. ${ }^{16}$

The results can be explained by the decrease in percentage of slowest brain wave, because that high percent of theta is associated with low attentional skills. ${ }^{17} \mathrm{Also}$, the increase of theta wave is related to lower blood flow and low glucose metabolization. ${ }^{18}$

Additionally, we highlight the effects of increasing fast waves $(12-16 \mathrm{~Hz})$, which is associated with increased cortical activation. ${ }^{19}$ Likewise, the improvements in visual and verbal memory skills coincide with the findings of Rostami ${ }^{20}$ that can be explained by changes in attentional control, which directly impact memory. ${ }^{16,21,22}$

The results of the study coincide with other investigations confirming the usefulness of NFB in increasing cognitive performance, ${ }^{23,24}$ and serves as a reference case to demonstrate the utility of NFB in the treatment of TBI sequelae. In this sense, NFB contributes to neuronal plasticity, correcting for training, excesses or deficits in frequencies. ${ }^{25}$

Limitations included the absence of long-term follow-up, limited monitoring of physiological variables, and comparison with subsequent electroencephalograms. The present study shows the need to replicate the intervention methodology used here with a representative sample of adult patients with TBI, with control group designs and long-term follow-up. 


\section{Conclusion}

Due to the incidence of brain accidents and their consequences on cognitive functioning, non-invasive therapeutic alternatives have been reviewed that demonstrate favorable effects on the overall performance of patients with TBI. In this case, the NFB efficacy to improvement of basic cognitive skills has been found, through a program of 20 sessions aimed at increasing low-beta waves and inhibiting theta waves.

The training program showed improvements in visual attention, explicit memory, working memory, verbal fluency and speed tasks after four months, results that shows an inversely proportional relationship with the average of percent theta waves. Additionally, increases in low-beta waves were observed, a finding related to greater cortical activation in the brain area close to the brain injury.

It is expected to continue a similar study with representative patients sample with TBI and control group to consolidate more evidence of the usefulness of NFB for the improvement of cognitive skills after brain injury.

\section{Acknowledgments}

None.

\section{Conflicts of Interest}

Authors report no conflict of interest.

\section{Patient Consent Form}

Patient authorized the intervention and disclosure preserved confidentiality of your personal data.

\section{References}

1. Cáceres D, Montoya Z, Ruiz A. Intervención psicosocial para el incremento de la calidad de vida en pacientes con trauma craneoencefálico moderado a severo. Revista Colombiana de Psicología. 2003;12:60-72.

2. Guzmán F. Fisiopatología del trauma craneoencefálico. Colombia Médica. 2008;39(3):78-84.

3. Junqué C. Secuelas neuropsicológicas de los traumatismos craneoencefálicos. Revista de Neurología. 1999;28(4):423-429.

4. Sánchez-Anguita A. Traumatismos craneoencefálicos y alteraciones neuropsicológicas. 2008;703:38-42

5. Ladera-Fernández V. Síndrome amnésico postraumático. Revista de Neurología. 200132(5):467-472.

6. Riaño-Garzón M, Raynaud-Prado N, Diaz-Camargo E. Seguridad Vial y Procesos Psicológicos: Acciones Preventivas. Logos Ciencia \& Tecnología. 2017;8(2):72-81.

7. Orrell M, Woods B, Spector A. Should we use individual cognitive stimulation therapy to improve cognitive function in people with dementia? BMJ. 2012344:e633.
8. Frank D, Khorshid L, Kiffer J, et al. Biofeedback in medicine: who, when, why and how? Mental Health in family Medicine. 2010;7(2):85-91.

9. Ato M, López J, Benavente A. Un sistema de clasificación de los diseños de investigación en psicología. Anales de Psicología. 2013;29(3):1038-1059.

10. Peña-Casanova J. Programa integrado de exploración neuropsicológica Test Barcelona. PIEN-B. España: Masson. 2005.

11. Wechsler D. Wechsler intelligence scale III. Manual Moderno, México. 2003.

12. Rey A. Test de copia y de reproducción de memoria de figuras geométricas. Tea ediciones. Madrid, Spain. 2009.

13. Krch D, Diaz-Orueta U, Santana E, et al. Rehabilitación de la Memoria: Historia, Factores Implicados y Enfoques de Tratamiento. Revista Neuropsicología, Neuropsiquiatría y Neurociencias. 2016;16(1):91-120.

14. Bernal C. Neurofeedback en niños con Trastorno por Déficit de Atención e Hiperactividad. Repositorio Digital Institucional CES. 2014.

15. Gadea M, Aliño M, Garijo E, et al. Testing the benefits of neurofeedback on selective attention measured through dichotic listening. Applied Psychophysiology and Biofeedback. 2016;41(2):157-164.

16. Calderón A, Cadavid-Ruiz N, Santos O. Aproximación Práctica a la Rehabilitación de la Atención. Revista Neuropsicología, Neuropsiquiatría y Neurociencias. 2016;16(1):69-90.

17. Swingle P G. Biofeedback for the brain: How neurotherapy effectively treats depression, AJDHD, autism, and more. Rutgers University Press, New Brunswick, USA. 2008.

18. Toomin H. Neurofeedback with hemoencephalography. Explore for the Professional. 200211:19-21.

19. Rostami R, Salamati P, Yarandi K, et al. Effects of neurofeedback on the short-term memory and continuous attention of patients with moderate traumatic brain injury: A preliminary randomized controlled clinical trial. Chin J Traumatol. 2017;20(5):278-282.

20. Meisel V, Servera M, Garcia-Banda G, et al. Neurofeedback and standard pharmacological intervention in ADHD: a randomized controlled trial with six-month follow-up. Biol Psychol. 2013;94(1):12-21.

21. Jiménez J, Hernández S, García E, et al. Test de atención D2: Datos normativos y desarrollo evolutivo de la atención en educación primaria. European Journal of Education and Psychology. 20125(1):93-106.

22. Quijano M, Arango J, Cuervo M. Neuropsicología del trauma craneoencefálico en Cali. Rev Cienc Salud, Colombia. 2012;10(1):21-31.

23. Evans JR. Handbook of neurofeedback: dynamics and clinical applications. Haworth Medical Press, New York, USA. 2007.

24. Bakhshayesh A, Hansch S, Wyschkon A, et al. Neurofeedback in ADHD: a single-blind randomized controlled trial. Eur Child Adolescent Psychiatry. 2011;20(9):481-491.

25. Larsen S, Sherlin L. Neurofeedback: An Emerging Technology for Treating Central Nervous System Dysregulation. Psychiatric Clinics of North America. 2013;13(1):163-168. 